\title{
Artículos
}

\section{Bancos de imágenes: evaluación y análisis de los mecanismos de recuperación de imágenes}

\author{
Por Jesús E. Muñoz Castaño
}

Resumen: El crecimiento de internet ha obligado a que las agencias de distribución de imágenes comercialicen sus fondos en la Red. Se evalúan en este artículo los sistemas de gestión de derechos de autor y de recuperación de imágenes desarrollados o puestos al servicio de los principales bancos de imágenes digitales, ofreciéndose también una valoración del estado de la cuestión en España. En la descripción de los sistemas de recuperación se han tenido en cuenta tanto criterios relacionados con un análisis conceptual como aquellos basados en los elementos intrínsecos de la imagen.

Palabras clave: Internet, Bancos de imágenes, Imagen digital, Propiedad intelectual, Análisis documental, Derechos de autor, Recuperación de imágenes, España.

\section{Title: Image banks: evaluation and analysis of image retrieval systems}

Abstract: The rise of internet has prompted image distribution agencies to market their stocks of images over the network. The present article evaluates existing systems for managing both image retrieval and copyright control that have been developed or applied by the major digital image banks. An assessment is also offered of the situation in Spain. In the discussion of image management systems, criteria are applied that relate to the conceptual analysis as well as to the inherent properties of the images.

Keywords: Internet, Image banks, Digital images, Intellectual property rights, Image indexing, Image retrieval, Copyright, Spain.

Muñoz Castaño, Jesús E. “Bancos de imágenes: evaluación y análisis de los mecanismos de recuperación de imágenes”. En: El profesional de la información, 2001, marzo, v. 10, n. 3, pp. 4-18.

La imagen como tal, independiente de su formato y soporte, había sido siempre un objeto de transacción, pero con la eclosión de los medios de comunicación de masas alcanzó una magnitud y connotaciones culturales desconocidas hasta entonces. La imagen fotográfica empezó a ser comercializada de la mano de agencias que gestionaban unos fondos destinados a satisfacer una demanda que iba alcanzando proporciones gigantescas. Por su parte el desarrollo de la imagen digital y de internet ha conllevado la proliferación de los bancos de imágenes. En esencia, se trata de colecciones que han sido digitalizadas y que, gracias a la utilización de motores de búsqueda basados principalmente en el empleo de palabras clave o descriptores, es posible consultarlas para su evaluación y adquisición.

La lógica que subyace en la creación de bancos de imágenes en internet es la propia del comercio electrónico, en lo que Philip Evans y Thomas S. Wurster (1999, pp. 28-29) han denominado el colapso de las "asimetrías de información". O lo que es lo mismo: cómo el desarrollo de las redes digitales ha traído consigo un canal de acceso universal que posibilita que un gran número de personas pueda intercambiar información valiosa sin la necesidad de intermediarios. El pa- pel que el profesional de la documentación debe jugar en este contexto pasa por el de adecuar las percepciones y necesidades de los potenciales usuarios con los criterios desarrollados por los bancos de imágenes para hacer accesibles sus fondos. Y todo ello sin olvidar que ese usuario es un cliente y que su espectro puede ser muy amplio y responder a necesidades muy diversas: fotógrafos que quieren saber si una imagen particular ya ha sido realizada, documentalistas buscando una en concreto, editores, público en general, etc.

Este artículo ahonda en la forma en que las imágenes, considerando previamente los derechos y limitaciones que les pueden ser aplicables, son tratadas documentalmente por los diferentes bancos de imágenes al tiempo que se valora de una forma sucinta el estado de la cuestión en España.

\section{Imágenes sujetas a derechos e imágenes de uso libre}

La organización de estos recursos refleja esa pluralidad de usuarios que mencionábamos y de hecho determina la división entre imágenes sujetas a derechos ("rights protected") y aquellas libres de los mismos ("royalty free") —aunque no por ello necesaria- 
mente gratuitas- Esta dualidad ha dado lugar a la generación de sitios web distintos con diferentes posibilidades de acceso y diversos servicios condicionando tanto la forma en que se tramitarán las ventas de las imágenes como su forma de pago. Por regla general, solamente las agencias tienen opción a adquirir las sujetas a derechos, lo que implica una negociación directa con la oficina central del banco de imágenes o sus representantes nacionales; con ello podemos ver que la globalización tiene sus límites.

\section{«No existen limitaciones para el uso de la imagen de una perso- na con un perfil público para usos no comerciales: libros de historia, noticias, etc.»}

Un caso representativo es Corbis, el banco de imágenes creado por Bill Gates, que en 1999 inició una política de expansión en el sector con la adquisición de Sygma - la agencia de periodismo fotográfico más grande del mundo con un archivo de 40 millones de fotografías- a la que ha seguido muy recientemente Saba y los bancos de imágenes The Stock Market y Sharpshooters. Corbis ha desarrollado tres parcelas de negocio a las que muy recientemente ha dado una nueva dinámica:

1. BizPresenter.com: está orientado a la venta de recursos gráficos tanto para el diseño web como para las "presentaciones" de corte corporativo.

http://www.bizpresenter.com/

2. Shopping: es un servicio pensado para audiencias más amplias de tal manera que sus imágenes pueden ser adquiridas para ser enmarcadas como grabados o pósters o descargadas en línea para uso personal.

http://www.shopping.corbis.com

3. Professional licensing, que a su vez encuadra cinco áreas:

-Traditional licensing: orientado a las imágenes sujetas a derechos ofreciéndose a los usuarios del Reino Unido, EUA y Hong Kong y pudiendo obtener información online sobre precios ajustados a una amplia variedad de usos; el resto de los potenciales clientes deberán seguir dependiendo de las diferentes agencias nacionales.

-Royalty free: el sitio para las imágenes libres de derechos que abarca categorías tanto de orden tecnológico, económico y del mundo de los negocios como gente y estilos de vida.

—News: servicio que permite realizar búsquedas mediante un sistema de recuperación mediante la utili- zación de operadores booleanos y lenguaje natural en los fondos de Sygma y Corbis Saba.

-Footage: es fruto de la asociación de Corbis con Sekani para la distribución de "clips". Enlaza directamente con el muy interesante sitio de Sekani.

- Corbis outline: dedicado a las imágenes de celebridades sin que sea posible la búsqueda de imágenes online.

http://www.corbis.com/professional

http://images.sekani.com

Los requisitos y las restricciones de acceso varían de un banco a otro y así, Corbis Traditional establece dos modos de registro:

a) Como miembro de pleno derecho, lo cual es bastante difícil si no se tiene una organización solvente que respalde la petición.

b) Con un registro simple, lo que supone que no se tiene acceso a la totalidad de los servicios y privilegios que tiene un cliente de pleno derecho.

\section{Directorios de bancos de imágenes}

a. Generales.

-Alba 36.

http://db.alba36.com/links/page = I \&kat $=$ I I-004\&lang=ENG

-Photoresource.

http://www.photoresource.com/resourcestock.html

-Yahoo.

http://www.dir.yahoo.com/business_and_economy/ shopping_and_services/photography/stock_ photography

b. España.

—Agenda de comunicación 2000.

http://www.la-moncloa.es/agendaco/framenti.htm

-Asociación Empresarial de Agencias de Prensa y Archivos Fotográficos.

http://www.aeapaf.org

-Proditors.

http://www.putput.es/proditors/html/presentacio.html

c. Otros recursos.

- The Trade Association for Stock Picture Agencies in North America.

http://www.stockindustry.org/

—The VisualEdge '98.

http://www.ibiblio.org/nppa/vel 
Tabla 1

\section{Conceptos abstractos}

- Conceptos variados

Abandono

Abundancia

Aventura

Admiración (Sorpresa): Reverencia

Ambición

$$
\text { Sorpresa }
$$

Americana

Anticipación

Austeridad

Autoridad

Burocracia

Estar ocupado

Precaución

Desafío

Cambio

Castidad

Comunidad

Competición

Complejidad

Concentración

Conformidad

Confusión

Conexión

Contrastes:

$$
\text { Opuestos }
$$

Control

Curiosidad

Delicado

Profundo

Deseo

Desolado

Difícil

Dirección

Disciplina

Descubrimiento

Ensueño

Sequedad

Misterioso

Esfuerzo

Vacío

Encanto

Resistencia

Igualdad

Erotismo

Etiqueta

Exageración

Feminidad

Fertilidad

Agitación

Futuro

Futurista

Crecimiento

Solidez

Pesado

Alta tecnología

Homenaje

Humildad

Humor:

Hambre
Imaginación

Incentivo

Indecisión

Individualidad

Indulgencia

Infinidad

Intensidad

Aislamiento

Liderazgo

Longevidad

Ruidoso

Suerte:

Abundancia

Lujuria

Mágico

Majestuoso

Masculino

Travesura

Misterio

Disconformidad

Obediencia

Obsolescencia

Oportunidad

Desbordante

Pareja

Pasión

Pastoral

Paciencia

Pensativo

Perseverancia

Filantropía

Pornografía

Poder

Practica

Precisión

Depredación

Presión

Orgullo

Progreso

Protesta

Tranquilidad

Rebelión

Responsabilidad

Rivalidad

Secretismo

Seducción

Sensualidad

Shock

Similitud

Simplicidad

Siniestro

Habilidad

Solemnidad

Velocidad:

Alta

Baja

Etapas de la vida: Madurez Vejez

Paternidad:

Paternidad

Maternidad
Embarazo

Juventud:

\section{Adolescencia} Niñez

Austeridad

Estereotipos

Estrategia

Fuerza

Lucha

Servil

Bochorno (clima)

Surreal

Rendición

Supervivencia

Temperatura:

Frío

Calor

Tentación

Sed

Tiempo

Timidez:

Vergüenza
Cansancio
Tradición
Arriba y abajo (sentido físico)

Variedad

Vulnerabilidad

Agotamiento

Húmedo

Abuso

Odio

Arrogancia

Aburrimiento

Conflicto

Daño

Muerte

Engaño

Derrota

Rechazo

Destrucción

Decepción

Asco

Desorden

Desesperación

Rutinario / Alienante

Alcoholismo

Diabólico

Exilio

- Conceptos negativos

Fracaso

Miedo

Locura

Frustración

Deprimente

Glotonería

Avaricia

Grotesco

Repugnante

Culpabilidad

Hastío

Odio

Infierno

Horror

Humillación
Impaciencia

Inseguridad

Irritación

Celos

Vagancia

Promiscuidad

Soledad

Perdida

Error

De pesadilla

Ominoso

Exceso de trabajo

Dolor

Pena

Prejuicio

Resignación

Venganza

Escasez

Vergüenza

Estrés

Tragedia

Fealdad

Vanidad

Vicio

Desperdicios

Debilidad

- Conceptos positivos

Logro

Admiración

Adoración

Cariño

Éxito

Aprecio

Asistencia

Lugares distantes

Equilibrio

Belleza

Despreocupación

Cariño

Limpieza

Comodidad

Confidencia

Cooperación

Valor

Artesano

Creatividad

Atractivo

Determinación

Devoción

Dignidad

Elegancia

Encorajar

Disfrute

Hilarante

Fama

Perdón

Resolución

Libertad

Nuevo

Amistad

Generosidad

Glamour

Bondad

Estilizado 


\begin{tabular}{|c|c|c|c|}
\hline Felicidad & Aves & - Estaciones y meteorología & - Hombres \\
\hline Saludable & Invertebrados: & Estaciones: & - Diversión \\
\hline Cielo & Arácnidos & Verano & - Religión \\
\hline Honestidad & Celentereos & Otoño & - Tercera Edad \\
\hline Honor & Crustáceos & Invierno & - Mujeres \\
\hline Esperanza & Equinodermos & Primavera & Ciencia y Tecnología \\
\hline Hospitalidad & Insectos: & Meteorología: & - Ordenadores e informática \\
\hline Idílico & Mariposas y & Rocío & - Medicina \\
\hline Independencia & lepidopteros & Niebla & - Espacio y astronomía \\
\hline Inocencia & Moluscos & Helada & Deportes y Actividades de aire \\
\hline Inspiración & Esponjas & Lluvia & libre \\
\hline Inteligencia & Gusanos & Nieve & - Ciclismo \\
\hline Intimidad & Mamíferos: & Tormenta & - Boxeo \\
\hline Justicia & Carnívoros: & Arte y arquitectura & - Golf \\
\hline Gentileza & Gatos & - Arquitectura & - Gimnasia \\
\hline Amor & Gatos & - Bellas Artes & - Montañismo y alpinismo \\
\hline Lealtad & domésticos & Espectáculos & - Caza y pesca \\
\hline Lujo & Leones & - Danza & - Artes marciales \\
\hline Vida nocturna & Linces & - Música & - Deportes de equipo \\
\hline Nostalgia & Tigres & Comida y Agricultura & Béisbol \\
\hline Optimismo & Perros & - Comida & Fútbol americano \\
\hline Organización & Perros domésticos & - Agricultura & Hockey sobre hielo \\
\hline $\mathrm{Paz}$ & Zorros & Industria y profesiones & Fútbol \\
\hline Poderoso & Lobos & - Negocios y comercio & Voleibol \\
\hline Exaltación & Herbívoros: & - Ingeniería y producción ma- & - Atletismo \\
\hline Prosperidad & Antílopes & nufacturera & - Deportes acuáticos \\
\hline Protección & Búfalos, bisontes y ga- & - Transporte & Navegación \\
\hline Pureza & nado bovino & Aviación & Submarinismo con bombona \\
\hline Relajación & Ciervos & Vehículos de motor & Submarinismo sin bombona \\
\hline Tranquilidad & Elefantes & Trenes y líneas férreas & Surfing \\
\hline Respeto & Jirafas & Transporte marítimo & Natación \\
\hline Reverencia & Cabras y ovejas & Paisajes y escenarios & Esquí acuático \\
\hline Romance & Hipopótamos & naturales & - Levantamiento de pesos \\
\hline Satisfacción & Caballos & - Desiertos & - Deportes de invierno \\
\hline Seguridad & Marsupiales & - Bosques & Hockey sobre hielo \\
\hline Soledad & Conejos y liebres & - Lagos, ríos y océanos & Patinaje sobre hielo \\
\hline Apoyo & Roedores & - Montañas y volcanes & Esquí \\
\hline Simpatía & Cebras & - Escenas rurales & - Atletismo \\
\hline Equipo & Primates & - Marinas & Viajar y cultura \\
\hline Ternura & Mamíferos marinos & - Cielos & - Gentes del mundo \\
\hline Confianza & Vida marina: & - Elementos relacionados con & Africa \\
\hline Verdad & Celentereos & el hielo y la nieve & Antártida \\
\hline Victoria & Equinodermos & Gente y estilos de vida & Asia \\
\hline Virtud & Peces & - Niños & Australia y Nueva Zelanda \\
\hline Riqueza & Mamíferos marinos & Maternidad & Europa \\
\hline Sabiduría & Esponjas & - Educación & Norteamérica \\
\hline Animales y naturaleza & - Plantas & - Vida diaria & Sudamérica \\
\hline - Animales & Flores & - Fiestas y vacaciones & - Lugares \\
\hline Anfibios y reptiles & Arboles y arbustos & - Relaciones humanas & - Viajes y turismo \\
\hline
\end{tabular}

Por el contrario, Tonystone, una empresa subsidiaria del grupo Getty Images, permite un registro común para Stone, PhotoDisc y Energy Film sin ningún tipo de limitación.

\section{http://www.tonystone.com}

Dentro del grupo de imágenes sujetas a derechos, encontramos dos tipos de éstos. Por un lado tenemos los de propiedad y explotación, que son gestionados por los bancos de imágenes y de los cuales pagan los correspondientes royalties a los autores. Por otro, los derechos de imagen ("model release"), que quedan fuera de la competencia de las agencias, aunque es co- mún que ofrezcan su asistencia para la tramitación. El derecho de imagen, o a la privacidad se refiere al poder de las personas para evitar una no deseada publicidad de su vida privada. Esto explica que pueda ser necesaria una autorización previa cuando una imagen en la que aparezcan no solamente personas sino también objetos, planos, edificios, etc.- - se utilice para fines comerciales. Por el contrario, no existen limitaciones para el uso de la imagen de una persona con un perfil público para usos no comerciales: libros de historia, noticias, etc. Por encima de todo no puede darse otro uso que el acordado en el contrato, siendo necesario un permiso expreso para su alteración. 
También se especifica cuántas veces la foto va a ser utilizada y de qué manera. Lógicamente el precio variará de acuerdo con el número de impresiones, el uso que se le quiera dar, el tamaño de la reproducción y el formato. Si el proyecto lo requiere, y si se tiene presupuesto para hacerlo, se puede garantizar su uso exclusivo en uno o varios países. do en la delimitación de categorías, el uso de descriptores y la redacción de títulos y pies de foto, aspectos que han sido muy tratados en la bibliografía especializada.

La definición de categorías permite clasificar la imagen dentro de un índice temático preestablecido (figura 1), para lo cual en la práctica se utiliza un tesauro o vocabulario controlado que lógicamente debe estar en consonancia con la naturaleza de la colección. Los sistemas de recuperación de los bancos de imágenes ofrecen esta posibilidad de búsqueda bien de una forma independiente, tal como puede verse en las categorías y subcategorías definidas en Corbis Royalty- Free, o integradas con una búsqueda mediante palabras clave, que es el modelo utilizado en la organización de Tonystone, cuyo sistema de búsqueda utiliza un tesauro de aproximadamente 25.000 términos adicionales. Esto significa que si se están localizando imágenes que reflejan la idea de "felicidad", se puede hacer una consulta de términos sinónimos como "alegría", "deleite" o "contento". O, tal como ocurre en Comstock donde un hiperenlace conecta directamente con una lista de palabras clave orientada a facilitar la definición de los términos de consulta.
Por el contrario, las imágenes libres de derechos una vez adquiridas pueden modificarse y utilizarse cuantas veces se desee para cualquier uso, comercial incluido, siempre y cuando esté en los límites de la ley. En general esto supone que no se garantiza un uso exclusivo de las mismas.

\section{El análisis y recuperación en función del contenido}

El modelo de análisis de la imagen que podemos encontrar en estos bancos responde a patrones con una amplia presencia en el campo del análisis documental. Sin embargo, como veremos más adelante, en los sistemas de recuperación que estas empresas están implantando en internet, empieza a ser notoria la utilización de los atributos intrínsecos de la imagen como elementos fundamentales para la indización y recuperación.

Uno de los principales problemas que presenta la descripción de este material es la forma en la que se representan los conceptos implícitos en ellos dada su peculiar riqueza visual y de contenido. Esto requiere de una verbalización de los mismos mediante un análisis documental, materializa-

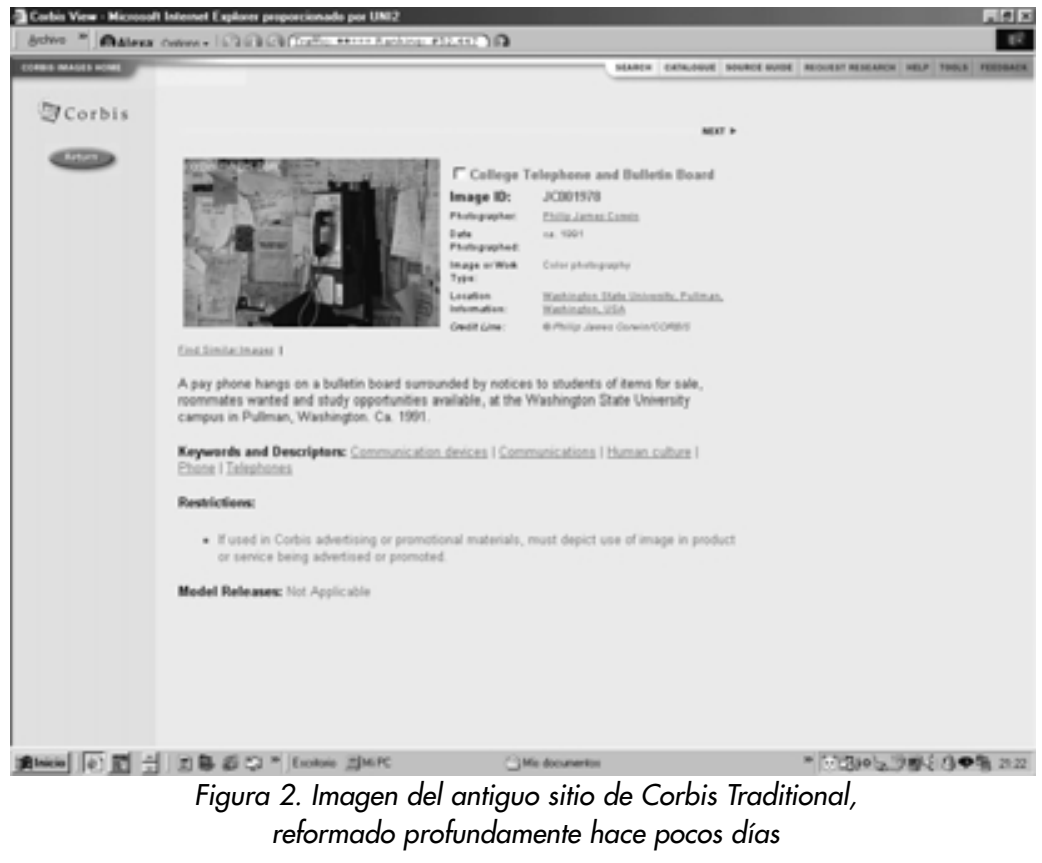


Figura 3

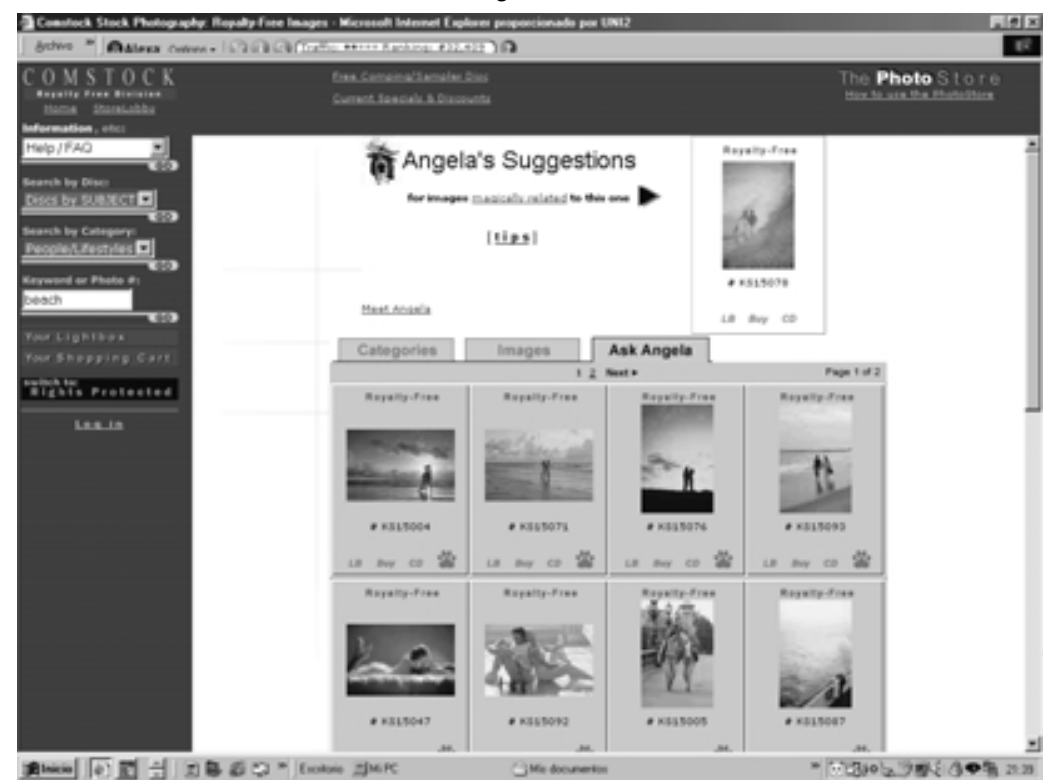

consultado libremente en Corbis Royalty-Free. Debe tenerse en cuenta que su inicial orden alfabético ha sido alterado dada su traducción al castellano.

A su vez, los sistemas de recuperación de los bancos de imágenes no dejan al margen la indización mediante la utilización del lenguaje natural. De hecho, la tarea resulta mucho más fácil porque el documentalista simplemente realiza asociaciones libres de conceptos con los objetos representados. El resultado es una indización más descriptiva pues los términos utilizados son únicos a cada fotografía y en donde el bien conocido paradigma de Lasswell es la piedra angular de la misma: supone una interrogación del contenido mediante los siguientes parámetros: "qué", "quién", "cómo", "cuándo" y "por qué".

\section{«En internet empieza a ser noto- ria la utilización de los atributos intrínsecos de la imagen como elementos fundamentales para la indización y recuperación»}

En los interfaces de recuperación, además de opciones simples se ofrecen sistemas de búsqueda avanzada donde es posible el uso simultáneo de encadenamientos booleanos y la aplicación de filtros de muy diversa naturaleza.

Por ejemplo en Corbis Traditional se puede observar la totalidad de filtros que están disponibles y que pueden ser agrupados de la siguiente manera (figura 6):

a. Según el uso de la imagen:

—Sujeta o no a "model release".

- Imágenes que se pueden obtener inmediatamente en diversas resoluciones.
-Restricciones aplicables a su uso: permite elegir el sector de actividad en el cual se quiere utilizar.

b. Relacionados con sus atributos intrínsecos.

c. Los que posibilitan restringir la búsqueda a determinadas categorías.

d. Aquellos que permiten determinar criterios como la utilización de un concepto, una localización particular, una acción o un determinado fotógrafo.

e. Establecimiento de un período específico.

En el caso de The Imagebank merece la pena destacar, dejando a un lado una serie de elementos intrínsecos que analizaremos más adelante y como ya hemos señalado anteriormente, una casilla de clarificación que utiliza la lógica del lenguaje $\mathrm{xml}$. Por ejemplo, si se introduce la palabra naranja preguntará si nos referimos al color o a la fruta. También es posible indicar directamente en la casilla de búsqueda "fruta: naranja". Estos filtros permiten refinar las búsquedas en un estado previo a la obtención de resultados. En este sentido es digna de resaltar la aportación de Comstock a través de los sistemas:

-Dynamic Visual Linking: funciona tanto para imágenes sujetas a derechos como para aquellas exentas de los mismos y permite iniciar una nueva búsqueda por medio de las categorías enumeradas en la imagen recuperada (figura 3). No debe olvidarse que en

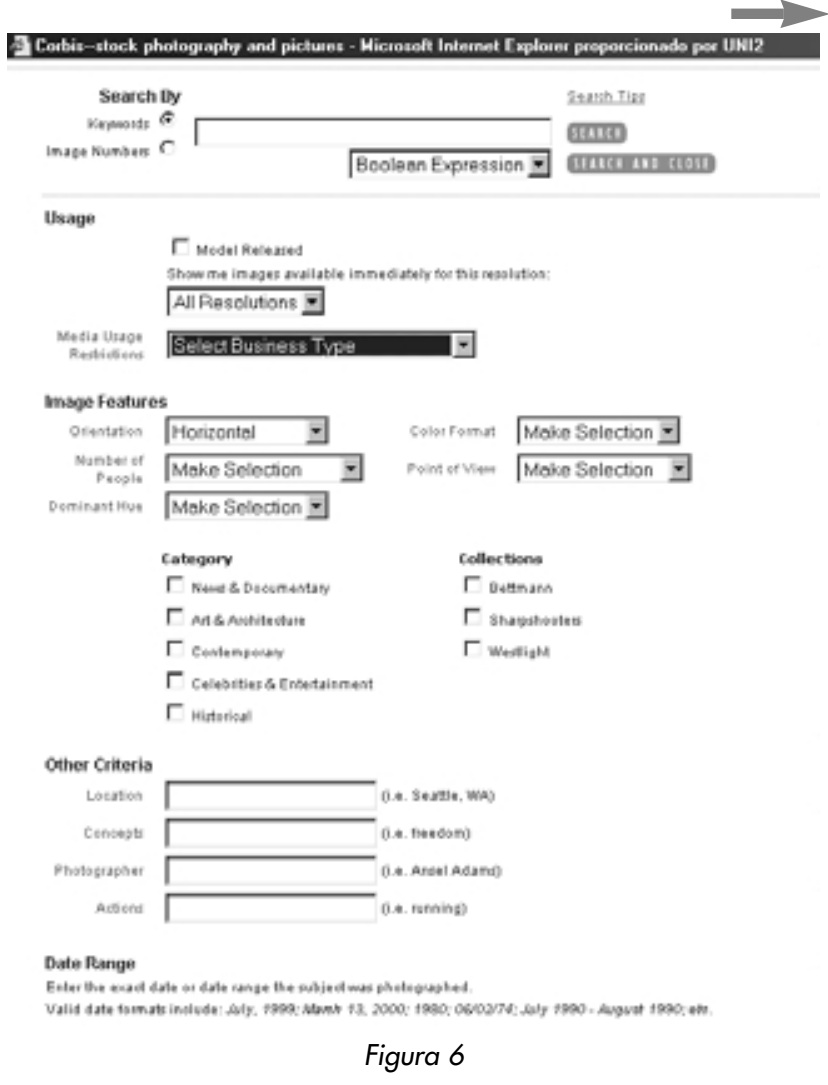


cualquier consulta realizada cuando se presentan los resultados aparece también un esquema arbóreo que señala las categorías que corresponden a las imágenes recuperadas.

\section{«Es significativo que los tesau- ros utilizados tengan tanto tér- minos con un contenido suma- mente específico como otros con un alto valor subjetivo, da- da la naturaleza y riqueza de contenido que una imagen pue- de llegar a representar»}

-Ask Angela: esta tecnología desarrollada por Comstock sólo funciona cuando no existe limitación por derechos de explotación. Se trata de un tipo de búsqueda visual y conceptual en donde cada imagen tiene asignado un algoritmo analítico que responde a un número de iconos ideográficos. A medida que se profundiza en la búsqueda utilizando más imágenes, se va recogiendo más información en el algoritmo, lo cual permite una mayor precisión en la siguiente.

\section{http://www.comstock.com}

La presentación de los resultados sigue pautas muy similares en la mayor parte de los bancos de imágenes:

-En una página preliminar se muestran las imágenes minimizadas organizadas en forma de mosaico que coinciden con el criterio establecido en la petición, o según el número que previamente se haya escogido en una casilla de preferencias. Si en su caso se presentan múltiples páginas de resultados es posible navegar a través de ellos saltando de una página a otra o seleccionando enlaces numerados para saltar a una especifica.

- Cada imagen de muestra suele llevar su título y un enlace que permite buscar otras similares. También es común un acceso al sistema de compra que permite depositarla en un "carrito de compra" o lightbox. Sin embargo, en relación con esta última opción debe reseñarse que no todos los bancos de imágenes permiten una compra online, al igual que su lógica puede variar si se trata de un sistema de imágenes libres de derechos o sujetas a ellos.

- La vista detallada de la imagen puede presentar información más específica (tal y como lo hacía la antigua versión de Corbis con una mayor riqueza documental que en la actual):

-Número de identificación de la imagen.

-Número o nombre del catálogo del cual forma parte.

-Título.
-Pie de foto.

-Palabras clave, que pueden servir de enlace a otras imágenes que también las contengan.

- Información sobre el fotógrafo.

-Derechos y restricciones a los que puede estar sujeta.

Debe tenerse en cuenta que algunos bancos de imágenes requieren que el usuario esté registrado para poder acceder a esta característica. Algo similar sucede con las imágenes ampliadas que pueden ser utilizadas como bocetos. Suelen tener baja resolución (por ejemplo $72 \mathrm{ppp}$ ), con un tamaño variable y con un peso que puede oscilar entre los 40 y $150 \mathrm{~Kb}$. Siempre tendrán visible un tampón (sello, que generalmente es el logotipo de la empresa insertado en la imagen) y en algunos casos una marca de agua o filigrana digital (señal de identificación, que no se aprecia visualmente, siendo necesario un editor de imágenes como PhotoShop para detectar su presencia).

\section{Los elementos intrínsecos de la imagen}

El simple hecho de analizarla desde el punto de vista de sus atributos visuales intrínsecos implica dotarla de un carácter estético que va más allá de su simple valor como fuente de información icónica. En este contexto, la imagen no tiene que ser vista exclusivamente como reflejo de una personalidad creadora sino también como el resultado de la aplicación de unos conocimientos técnicos que influyen en gran manera a la hora de determinar un importante número de sus rasgos.

Estos fundamentos técnicos pueden ser instrumentalizados como elementos de descripción y entrar a formar parte del vocabulario normalizado utilizado para indizarla. De hecho, algunos bancos de imágenes como Tonystone, Corbis y The Imagebank están utilizando estos criterios como una variable más dentro de su sistema de búsqueda. Por su parte, la gran totalidad de ellos permiten opciones de filtrado como:

-Orientación: todas las orientaciones, vertical, horizontal y panorámica.

-Sólo fotos: blanco y negro o color.

En primer lugar, utilizan una serie de claves técnicas como descriptores. Así en el caso de Tonystone encontramos:

-Interior, exterior o foto de estudio.

-Punto de vista: de frente, aérea y de ángulo bajo.

-Color: color, blanco y negro, sepia o coloreado a mano. 
-Otros términos como bodegón, primer plano, movimiento barrido, foco difuso, imagen transferida, montaje generado digitalmente, zoom o infrarrojo.

The Imagebank utiliza conceptos similares como:

-Color: color, blanco y negro, sepia, infrarrojo.

-Colores específicos: azul, verde, rojo, amarillo, púrpura, naranja, marrón, blanco, negro, gris, rosa, beige, oro, plata.

-Otros términos técnicos: primer plano, plano largo, aéreo, difuminado, montaje, destacar (quitar fondo), foto digital, etc.

En segundo lugar permiten definir el formato de la imagen: horizontal, vertical, cuadrado o panorámico y si aquellas que deben recuperarse lo deben ser en blanco y negro, color o ambas.

Por su parte, Corbis Traditional establece la siguiente serie de filtros:

—Número de personas: una, dos, tres o más, grupos o multitudes.

-Tonalidad dominante: verde, azul, magenta, naranja, rosa, púrpura, rojo y amarillo.

—Orientación: horizontal, vertical o panorámica.

-Color: blanco y negro o color.

-Punto de toma: aéreo, primer plano, exterior, interior, vista desde arriba, desde abajo o desde el espacio.

El valor documental de estos principios, como también veremos más adelante analizando otros elementos propios de la composición de la imagen, es im-

Figura 5

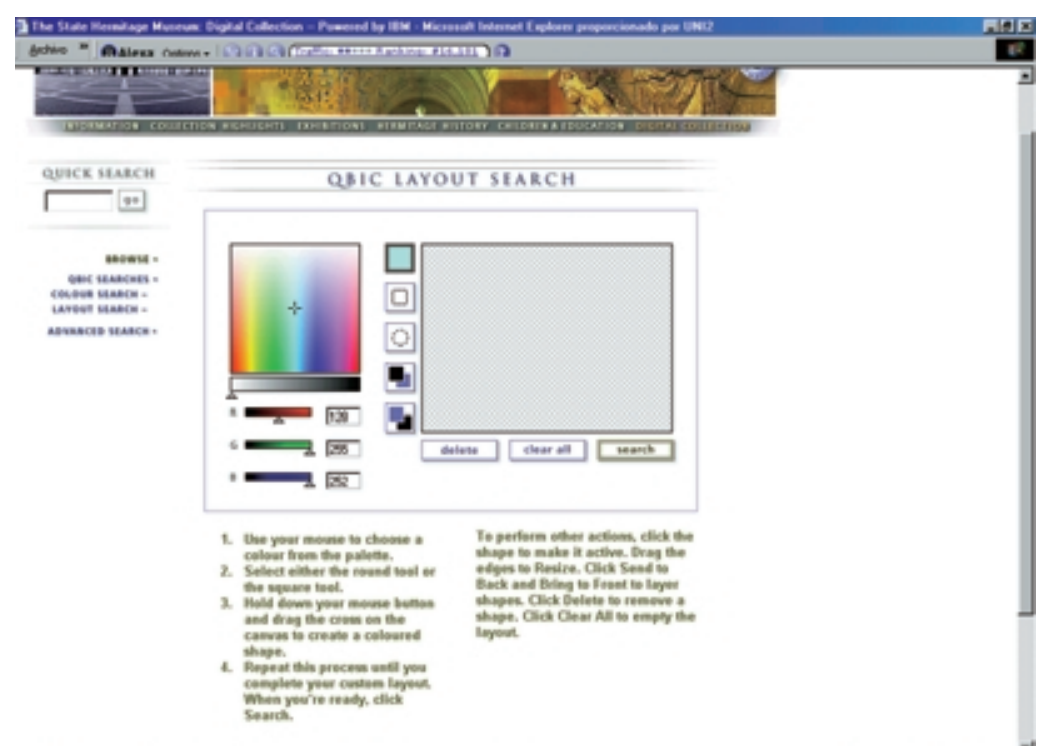

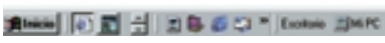

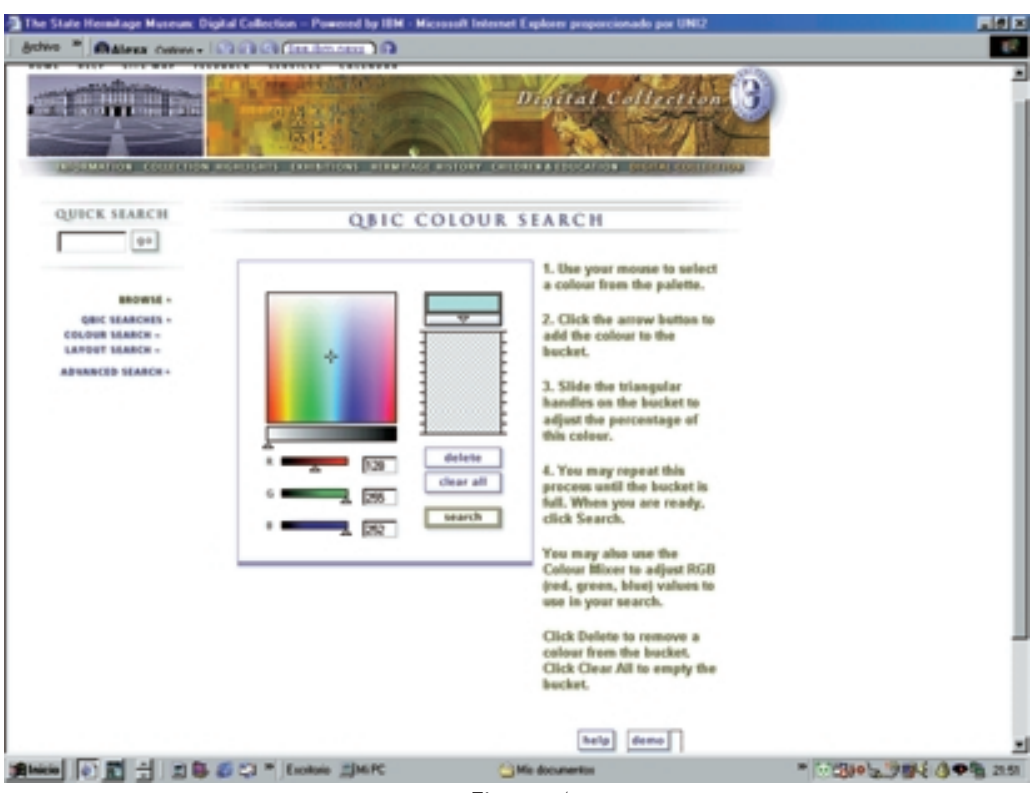

Figura 4

portante. Por ejemplo: un formato vertical da una dimensión más vertical a los elementos que componen una escena. Existe una sensación de menor sujeción al suelo y esto proporciona al sujeto principal un efecto más dominante e imponente. Las líneas verticales se intensifican probablemente por que se tiende a comparar los elementos superiores del cuadro con los inferiores en lugar de hacer una equiparación entre los de la derecha y la izquierda. Por su parte, un encuadre horizontal parece dar más intensidad a los movimientos horizontales y a las líneas estructurales, especialmente cuando el formato es largo y estrecho (panorámico). En los paisajes ayuda a dar importancia a la línea del horizonte y produce una sensación panorámica y de estabilidad. Un formato cuadrado produce un efecto de simetría y equilibrio dado que cada esquina se distancia del centro en igual proporción. Finalmente, el formato ovalado o redondo propio de las cámaras panorámicas puede ser utilizado para delimitar composiciones a la manera en que se llevaban a cabo en los orígenes de la técnica fotográfica.

Paralelamente se empieza a vislumbrar en el mercado la presencia de modelos de recuperación basados en el análisis de atributos intrínsecos de la imagen como el color, contornos o figuras, texturas y estructuras espaciales. Son procedimientos que no se utilizan de forma exclusiva en tanto que conviven con los tradicionales sistemas conceptuales.

Query By Image Content (Qbic), de IBM, permite realizar búsquedas basadas en el contenido visual, tanto determinando porcentajes de colores como mediante la distribución de éstos y de las texturas presentes (figura 4). Si bien parten del mismo princi- 
pio, las propiedades visuales de las imágenes, se trata de dos sistemas de búsqueda como se puede ver en la aplicación que hace del mismo el museo del Hermitage (figura 5).

http://www.qbic.almaden.ibm.com

\section{http://www.hermitagemuseum.org}

Pueden convivir con los métodos tradicionales de búsqueda mediante descriptores pero no pueden combinarse con ellos, ni entre ellos, para llevar a cabo una consulta unitaria que aprovechase el potencial de cada una de las modalidades.

\section{«En el caso de The Imagebank merece la pena destacar una ca- silla de clarificación de las pre- guntas que utiliza lenguaje $\mathrm{xml»}$}

Excalibur Visual RetrievalWare SDK 2.1 es un instrumento de programación pensado para desarrollar aplicaciones orientadas a la indización y recuperación automática de imágenes. Se basa en el propio modelo que representa la imagen y en los valores adicionales de color, composición y contraste, a los que dota de un código binario ("algoritmo de retina") de unos y ceros para identificarlos en cada una de las imágenes; al mismo tiempo, los usuarios pueden definir otros campos de búsqueda. El análisis parte del estudio de la disposición de los píxeles y puede ser adaptado a una serie de parámetros previamente determinados por el analista (filtros que depuran las imágenes). Por lo tanto quedan clasificadas en términos de color, forma y textura como ya hemos visto en el otro modelo.

\section{http://www.excalib.com/products/vrw/shtml}

El sistema entiende la imagen de una forma diferente a como nosotros la percibimos: un gato se presenta no por lo que nosotros entendemos como tal, sino por un conjunto de puntos oscuros y brillantes. De esta manera las recuperaciones se hacen en función de valores visuales, no conceptuales. A su vez se parte de un principio diferente del anterior, que fue desarrollado para el reconocimiento de caracteres kanji escritos a mano (símbolos japoneses adaptados del chino). En el fondo nos encontramos con una cuestión similar al descubrimiento que el impresionismo - y especialmente el postimpresionista movimiento puntillistahicieron la fotografía y las nuevas corrientes de investigación en el campo de la óptica. En esencia, se puede establecer un parangón entre los píxeles de una imagen digital y el granulado de una película de fotografía.

La utilidad de este precepto en términos documentales está en intima relación con los propios principios que sirven de fundamento a la técnica fotográfica. Así, hablar de textura es hablar de superficie. Su aspecto visual viene dado por el carácter del material, lo que también nos insinúa su tacto. Aquellos sujetos que contienen una rica mezcla de texturas son especialmente reconocidos por su capacidad de contraste $u$ oposición con los demás.

Por su parte, el color es en sí un elemento con valor propio que contribuye enormemente a la enfatización y a la apariencia que se desea dar a una fotografía; la relación entre los colores del objeto junto con el color predominante de la iluminación puede tener un efecto armonioso o discordante. Su combinación es también importante: aquellos colores que aparecen juntos en el espectro tienden a mezclarse mientras los que están separados son propensos al contraste. Paralelamente las tonalidades determinan el efecto dramático y sensorial de la imagen. Una coloración limitada o sombría acentúa la intensidad de un paisaje romántico o la utilización del rojo o el amarillo sugiere luz y calor. En cambio, una tonalidad ligera insinúa delicadeza, espacio y suavidad. Todo ello sin olvidar que el color es también el fundamento de la perspectiva aérea y en consecuencia, con la distribución de las tonalidades de color, se consigue una mayor sensación de profundidad y distanciamiento especialmente en los paisajes.

En líneas generales, la comparación y clasificación de imágenes en Excalibur se realiza equiparando los índices asociados a cada una de ellas mientras que los índices generados se recogen en una base de datos. El proceso de recuperación se inicia eligiendo una base de datos y seleccionando la imagen que va a ser utilizada como modelo. En unos segundos se obtiene una pantalla con muestras similares a la previamente elegida, con las cuales es posible:

- Seleccionar una y utilizarla como referencia para una nueva búsqueda.

- Navegar entre las imágenes almacenadas en los directorios de donde las muestras se han obtenido.

- Borrar o mover archivos.

—Pegarlas en otras aplicaciones o archivos.

- Ver y editar cualquier imagen en la ventana de edición.

Los creadores reconocen la existencia de ruido documental en los resultados recuperados ya que el sistema no puede distinguir pequeñas diferencias de traducción, rotación y escala entre las imágenes recuperadas. Para compensarlo los resultados se presentan en un orden en donde las imágenes más similares ocupan los primeros puestos; entre ellas se encontrarían otras 
con tonos diferentes pero intensidades de luz que coinciden con la muestra.

El procedimiento de recuperación se puede organizar inicialmente con algunos de los índices desarrollados de acuerdo con el algoritmo de retina y después, en una segunda consulta, con los resultados obtenidos utilizando los tradicionales algoritmos de correlación (basados en el análisis del contenido de la imagen). En sí, es un sistema muy ágil dado que la recuperación e indización se desarrollan a gran velocidad, ya que en el fondo se trata de dos bases de datos: una con las imágenes y otra con los algoritmos que las representan y que supone un $1 \%$ de la anterior.

Está diseñado para trabajar fundamentalmente con imágenes bitonales o en color de dos dimensiones y con formatos simples tiff, jfif (jpeg), GIF, BMP, PNG, PPM y ddif así como con formatos múltiples mpeg y FIT. Éstas pueden ser capturadas por una cámara, $V C R$, u otra fuente de vídeo: un escáner de mesa o portátil, internet o un editor de imágenes. Dos direcciones de la Red permiten ver el sistema en funcionamiento. Se trata de Yahoo Image Surfer e Image Assets.

\section{http://isurf.yahoo.com}

\section{http://www.image-assets.com/cgi-bin/vrwsdk/cst/picsea}

El principal problema que plantean estos modelos de recuperación es que su uso se constriñe a un plano general dadas las limitaciones que ofrecen. Tal y como estamos viendo, la riqueza de la imagen se encuentra en los múltiples matices que entran en juego y que difícilmente podrán ser representados en su totalidad por unos sistemas de estas características en su estadio actual: brillos, sombras, contrastes, tonalidades, etc. A su vez, tampoco puede ser analizada exclusivamente en función de su color, salvo determinadas obras donde sea el elemento principal. No es casual que cuando se llevan a cabo búsquedas en el Hermitage la mayor parte de las obras recuperadas corresponden al movimiento impresionista y evoluciones posteriores, en una línea similar a lo que señalábamos antes.

Si el objetivo es reducir el tiempo de indización, los resultados no van a la par de las expectativas dado que se necesitaría seguir analizando otros elementos de la imagen. Sin embargo, un instrumento de estas características es útil para establecer los colores y tonos dominantes como un campo más de búsqueda. Esto

Leer EPI es como asistir a un curso de formación continua pero con el horario acomodado a tus necesidades. supondría que tendrían que dejar de operar aisladamente y pasar a integrarse con otros criterios de recuperación para poder combinarse con los mismos a la hora de elaborar una búsqueda.

\section{Directorio de bancos de imágenes en España con presencia en la Web}

Este apartado pretende mostrar la mayor parte de las agencias fotográficas españolas que pueden encontrarse en la Red. La información y prestaciones que ofrece cada sitio web son muy desiguales: algunos sólo constan de una mera pantalla de presentación, otros solamente ofrecen una muestra generalista de sus servicios y finalmente un grupo participa totalmente de la lógica del comercio electrónico, aunque con diferentes soluciones y resultados.

\section{Agefotostock.}

Con sede en Barcelona cuenta con representaciones en Madrid, Bilbao y Nueva York y dentro de su fondo variado se ofrece la posibilidad de distribuir los trabajos de fotógrafos independientes. A pesar de su sistema de búsqueda en internet no es posible la compra online. Tras elegir la foto y rellenar un formulario electrónico la agencia se pone en contacto con el cliente para dar una respuesta a la petición, presupuesto incluido. Las imágenes se pueden recibir:

-Vía e-mail en un fichero jpg a un tamaño de 25 $\mathrm{Mb}$ comprimido a $2 \mathrm{Mb}$.

—En un cd-rom a un tamaño a $72 \mathrm{Mb}$.

-En transparencia $6 \times 7 \mathrm{~cm}(70 \mathrm{~mm})$.

- Mediante fichero digital hasta $72 \mathrm{Mb}$ (comprimido a $6 \mathrm{Mb}$ aproximadamente) por transmisión rdsi (isdn) vía FotoTransmit. La recepción se realiza en menos de 24 horas a partir de que se confirma el acuerdo con la tarifa del uso de la/s imagen/es.

http://agefotostock.com/main.htm

\section{Aisa.}

Al igual que en el caso de Oronoz, su sitio web es meramente testimonial.

http://www.aisa-bcn.com

\section{Api Photo Press.}

De nuevo una única página que indica solamente que se realiza todo tipo de fotografía de prensa y reportajes en el área de Andalucía y el escaneado en 35 mm de Nikon.

http://personal.redestb.es/api/service.htm 


\section{Artplus.}

Ofrece una galería de fotógrafos españoles con portafolio.

\section{http://www.artplus.es}

\section{Carlos Virgili/Risck.}

Especializados fundamentalmente en tres temas: fauna y flora, islas y países pequeños así como en reportajes sobre deportes de riesgo y aventura e incluyen un anexo con los reportajes filmados. Cuenta con un archivo de 40.000 diapositivas seleccionadas, parte de ellas disponibles en cd-rom sin que ninguno de sus fondos esté disponible online.

http://personal4.iddeo.es/risck/frame_e.htm

\section{Contifoto.}

Establecida en 1961 en Madrid y con oficina de ventas en Barcelona. Actualmente representa a más de 50 agencias, fotógrafos y revistas de todo el mundo, contando en España con la producción de numerosos redactores gráficos que les proporcionan reportajes y fotografías desde todo el país. Dispone también de un archivo que supera los tres millones de imágenes que pueden ser transmitidas en alta definición por línea $r d$ si. Asimismo, pueden realizar reportajes y fotografías por encargo en cualquier punto de España.

http://www.contifoto.com

\section{Cover.}

Es una agencia de fotografía española con representación en diversos países fundada hace 20 años y compuesta por más de 100 fotógrafos, con más de un millón de imágenes presentadas en más de diez catálogos. Consta de las siguientes secciones:

-Archivo histórico: supera el millón de imágenes con todos los contenidos relacionados con la historia, personajes, arte, geografía y temas sociales del panorama español y algunos internacionales de los últimos 20 años. En la actualidad se está digitalizando lo mejor y más representativo que estará disponible en breve online.

-Actualidad: es una colección de política, cultura, deporte y vida social. En un futuro entrará en funcionamiento Cover online, un servicio permanente de acceso a toda su producción de actualidad y reportajes a través de la Red.

-Retratos: cuenta con más de mil fotografías de los personajes más relevantes de la vida social, cultural, económica y política.

De momento se atienden personalmente todos los pedidos y encargos al tiempo que su archivo realiza una búsqueda de fotografías documentadas bajo las es-
El profesional de la información está abierto a todos los bibliotecarios, documentalistas y profesionales de la información, así como a las empresas y organizaciones del sector para que puedan exponer sus noticias, productos, servicios, experiencias y opiniones.

Dirigir todas las colaboraciones para publicar a:

El profesional de la información

Apartado 32.280

08080 Barcelona

Fax: $+34-934250029$

epi@sarenet.es

pecificaciones y uso de los clientes. Su envío se puede realizar por rdsi, módem y soporte digital o analógico (diapositivas y b/n). Recientemente ha introducido un sistema de búsqueda muy simple orientado a la recuperación de imágenes de actualidad y que tiene un carácter sumamente restrictivo tanto en los términos de obtención adicional de información como en lo relativo a la descarga de las mismas en tanto que es necesario un registro previo.

\section{«No todos los bancos de imáge- nes permiten la compra online, al igual que su lógica puede va- riar si se trata de un sistema de imágenes libres de derechos 0 sujetas a ellos»}

Además ofrece catálogos de las agencias que representa en España:

-Photonica: agencia de vanguardia y siempre un paso por delante de las últimas tendencias del mundo de la publicidad y editorial. El banco de imagen más completo y sofisticado del mundo. tronomía.

- Space Photos con cientos de fotografías de ashttp://www.cover.es 


\section{Efe.}

Aunque cuenta con 13 millones de negativos con la historia gráfica del siglo XX sólo se ofrece una simple y testimonial galería online. Para acceder al servicio de infografía se necesita una clave sin que en ningún lugar del sitio web se informe sobre el mismo.

http://www.efe.es

\section{Ferypress.}

Agencia de fotografía deportiva con una web que en un principio no ofrecía ningún tipo de información, ni siquiera corporativa. La búsqueda se realizaba mediante:

-Un sistema de imágenes de mosaico (de publicidad) pasando de una pantalla a otra mediante hiperenlaces.

- Una lista de categorías que enlazan a páginas con imágenes de muestra en mosaico.

No se ofrece ningún tipo de información sobre ellas y tampoco poseen tipo de tratamiento documental alguno, no existiendo la posibilidad ni de comprar ni de solicitarlas online. Hoy en día se encuentra en construcción.

http://www.ferypress.es

\section{Index.}

Recoge fotografías de publicidad, paisajes, bodegones, deportes, arte, cine, industria, viajes, negocios, naturaleza, historia, personajes, arquitectura, ciencias, gente, etc., gestionando comercialmente el fondo de imágenes de la Generalitat de Cataluña. No hay consulta online y solamente se ofrece una lista de catálogos que pueden pedirse por teléfono o correo electrónico junto con un acceso directo a StockDirectory y una pequeña galería de imágenes. Se pueden solicitar fotografías por correo electrónico y fax, garantizándose un servicio de entrega en 24 horas.

http://www.stockdirectory.com

http://www.indexfototeca.es/INDICE2.html

\section{Magic Image.}

Comercializa imágenes de ámbito nacional e internacional que representan diversas localidades españolas y brasileñas. Se consultan en una galería que utiliza hiperenlaces y se solicitan a través de e-mail.

http://www.magicspain.com/indexsp.html

\section{Miguelez Sport Foto.}

Agencia de prensa española, dedicada única y exclusivamente al deporte en sus múltiples facetas: fútbol, atletismo, baloncesto, gimnasia, artes marciales, deportes de aventura y riesgo, motociclismo, automovilismo, balonmano, tenis, golf, etc. Comenzó en 1991 con el nombre Temp Sport España, idéntico al de la prestigiosa agencia francesa Temp Sport, con la que tiene una activa relación comercial y de intercambio de fotografías. Sin embargo desde su entrada en internet cambió su denominación para evitar posibles errores sobre el origen de las fotografías entre los clientes de las dos agencias. Está representada en Alemania, Italia, Francia, Portugal y Japón por agencias de esos países.

\section{Próximos números monográficos}

Mayo 200I Información para la inteligencia competitiva

Septiembre 200I Archivos digitales en empresas y organizaciones

Diciembre 200I Intranet y documentación

Marzo 2002 Automatización de bibliotecas

Los interesados pueden remitir notas, artículos, propuestas, publicidad, comentarios, etc., sobre estos temas a: 
Ofrece una amplia colección de fotografías sobre todos los deportes (retratos, acción, deportistas, ilustraciones, estadios, etc.) de producción propia y de agencias extranjeras, de las que tiene delegación para España. Además de ofrecer las que tienen en archivo, pueden realizar toda clase de reportajes gráficos para aquellos clientes que deseen un servicio más exclusivo.

De momento su banco digital se ha volcado en el fútbol, por ser el deporte que más demanda tiene entre la mayoría de sus clientes, ofreciendo más de 2.000 fotografías de futbolistas, equipos, entrenadores, etc., de la liga española. También se pueden encontrar los jugadores de fútbol de la Selección nacional. Van añadiendo otros deportes.

http://www.miguelezsports.com

\section{Oronoz.}

Tan sólo ofrece una página de presentación sin ningún tipo de información o servicio online.

\section{http://personal.redestb.es/oronoz}

\section{Photobanc.}

Empresa centrada en servicios integrales para archivos fotográficos, digitalización, trabajos fotográficos y de edición y formación. Ofrecen su asistencia para la promoción de este tipo de archivos fotográficos para colaborar en su difusión. Sus fondos, que pueden adquirirse a través de Digital Press, incluyen imágenes históricas y actuales: historia, deporte, cultura, religión, industria, personajes, cine, etc.

\section{http://www.photobanc.com}

\section{Photonline.}

Se trata de un grupo de agencias que han creado un portal con un amplio archivo que incluye fondos sobre la guerra civil y la transición, política en general, deportes, cine, botánica y la obra de destacados fotógrafos. Las agencias integradas en este proyecto son:

-Alfaquí: oficina de prensa y fotografía informativa cuyo archivo recoge fotografías relacionadas con España: lugares y ciudades de interés turístico, monumentos, rutas, fiestas populares, sociedad, deportes, toros, restaurantes y paradores, naturaleza y fauna. Atiende encargos fotográficos para medios informativos y facilita fotógrafos en España para trabajos de corresponsal y enviados especiales al tiempo que cubre coberturas deportivas.

- A-Z Imagen: representa a fotógrafos que cubren diferentes áreas temáticas. Está especializada en fotografías de: ciencias de la naturaleza (geografía, geología, biología, botánica, zoología, ecología y microfotografía), niños (desde el parto hasta la edad escolar), personalidades (cultura, deporte, política y espectácu- los) y Barcelona (arquitectura, escultura, urbanismo, sociedad y eventos).

-Digital Press: cuenta con una gran implantación en el mercado norteamericano y latinoamericano. Sus contenidos abarcan desde política, paisajes, retratos de actores y escenas de toda la historia del cine, botánica de los cinco continentes, imágenes de ilustración hasta fotografías de la guerra civil, la transición democrática así como archivos de los fotógrafos más destacados del país.

\section{«Se empieza a vislumbrar la presencia de modelos de recu- peración basados en el análisis de atributos como el color, con- tornos o figuras, texturas y es- tructuras espaciales»}

- Global Photo: portal de fotografía francés que aglutina unas veinte agencias de todo el mundo con los contenidos más variados.

-New China Pictures Company (Ncpc), de Xinhua, la agencia oficial china, con un archivo que supera los 6.000.000 de imágenes de la actualidad política y social del país. Su contenido abarca desde la Dinastía Quing, la época de la República (1911-1949), período anti-japonés (1937-1945), guerra civil, guerra de Corea y los acontecimientos políticos, culturales y sociales más destacados hasta nuestros días.

-Photogalería.net es la primera web especializada en fotografía de autor española. En ella se dan cita los mejores fotógrafos nacionales con imágenes de gran personalidad que abarcan tanto las de reportaje como galerías de personajes importantes. Este archivo tiene a la venta más de 5.000 imágenes. Tanto para descargar las muestras en baja resolución como para comprarlas en alta calidad se debe rellenar un formulario (con entrega de una contraseña en menos de 24 horas).

http://www.photonline.net

\section{Prisma.}

Ofrece solamente una breve reseña sobre sus servicios de fotografía aérea.

http://www.prisma.cllfotograf.html

\section{Queen International.}

Para disfrutar de los 3 servicios ofrecidos se necesita una clave de acceso:

-Fotoservice: sistema online de acceso a fotos de actualidad. Esta sección es actualizada diariamente, pasando las fotografías al banco de imagen cuando 
cumplen 15 días de antigüedad. Permite descargar fotos de alta resolución en unos pocos segundos.

-Banco de imagen: base de datos organizada por secciones temáticas entre las que cabe destacar las dedicadas al mundo de la moda, la imagen publicitaria y corporativa, naturaleza, paisajes y viajes, fotografía erótica y toda la imaginería de prensa, desde fotografías de personajes famosos hasta instantáneas de deportes y noticias de todo tipo.

-Páginas de exclusivas: la agencia representa la producción de fotógrafos, agencias y revistas, nacionales y extranjeros en España y otros países.

http://www.queen-int.com/main.php3

\section{Seridec.}

Simplemente actúa como intermediario en la venta de series de CDs y algunas imágenes de las agencias Apply Pictures, Aridi, BeeLine, Central Stock, Creativ Collection, Digital Vision, ElektraVision, Flat Earth, GeoAtlas, GoodShoot, IllustTank, Image100, ImageIdeas, John Foxx Images, LifeArt, Nova Development, PhotoAlto, PhotoDisc, PhotoEssentials, PhotoSpin, Phovoir, Scorpius y StockByte. No hay venta online y solamente se señalan tarifas y enlaces a las páginas web de las compañías señaladas anteriormente.

http://www.seridec.com

\section{Stockphotos.}

Stock Photos España, agencia inaugurada en 1989, presta servicios generales de archivo fotográfico y pertenece al grupo Latin Stock, una organización instalada en Argentina, Brasil, Chile, México, España, Colombia, Venezuela, Perú, Uruguay y Ecuador dedicada al suministro de imágenes y contenidos en general a la industria publicitaria, editorial y televisiva tanto de América Latina como de España. Sus fondos de archivo cuentan con más de 2.000.000 de fotografías y gestiona el envío de imágenes desde su oficina en Madrid a cualquier punto de España en menos de 24 horas. Se ofrecen tanto analógicamente como en cualquier formato digital. Las que se encuentran digitalizadas se pueden obtener rápidamente mediante 3 caminos distintos:

—En cd-rom en formato tiff y cmyk.

— Transmisión mediante rdsi en formato jpeg $\mathrm{y}$ cmyk.

-A través de su espacio web se pueden obtener las solicitadas en alta resolución en formato jpeg y cmyk.

La consulta en línea, en inglés, se realiza a través de una web común con otros países y se necesita clave de acceso para:
—Búsquedas en alta resolución.

- Ampliar las imágenes de muestra en mosaico obtenidas en una petición realizada en baja resolución.

—Utilizar carpetas donde guardar las imágenes recuperadas.

-Hacer encargos online.

A su vez, representa en España a numerosas agencias internacionales de fotografía de reconocido prestigio, entre las cuales destacan:

-The Stock Market (publicitaria general).

-Sharpshooters (publicitaria general).

—Index Stock Imagery (publicitaria general).

-Stock Image (publicitaria general).

—It Stock International (publicitaria general).

—Zefa Visual Media (publicitaria general).

-Ace (publicitaria general).

_Ibid (conceptual en b/n destinada al mercado publicitario).

-Custom Medical (médica y científica).

—Bernard Seigneury (médica y científica).

_Inside (especializada en decoración y alimentación).

—La Photothèque (publicitaria general).

— Stock Food (especializada en cocina y alimentación).

—Bios (naturaleza y animales).

-Voller Ernst (humorística).

—Topham Picturepoint (histórica).

-Altitude (aérea).

-Bilderberg (grandes reportajes).

—Laif Photos (grandes reportajes).

-Bilderdienst Fotoagentur (decoración).

-Picture Press (decoración y belleza).

De todas ellas distribuye gratuitamente a sus clientes más de 30 catálogos. Las condiciones para el envío de fotografías de catálogo son las mismas que las de archivo, únicamente deben indicarse las referencias de las que se desean recibir. También hay catálogos disponibles en cd-rom con una resolución de 72 ppp. Los derechos se negocian con Stock Photos y ellos envían la diapositiva o el fichero digital en alta resolución.

http://www.stockphotos.es/default1.htm 


\section{Zardoya.}

A pesar de su importante archivo de historia, personalidades, geografía, estilos de vida, arte, glamour y deportes, su página web está sólo dedicada a la representación de agencias y colecciones internacionales:

-Attard: de nacionalidad británica con un fondo de alto contenido estético y una colección especializada de fotografías de hombres, mujeres y parejas en situaciones diversas.

- Camera express: fundada en 1947, con un fondo de cerca de 10 millones de fotografías. La sede se encuentra en Los Ángeles y cuenta con una red internacional de fotógrafos que cubren los acontecimientos mundiales más importantes, temas de interés humano, belleza y moda, viajes, naturaleza y humor, así como actividades de personajes famosos.

-Iconos: se trata de una agencia francesa con sede en Lyon que representa a más de 50 fotógrafos y posee un fondo de más de 1 millón de fotografías con un extenso archivo de la región de Rhône-Alpes. Está especializada en producciones fotográficas de carácter publicitario que en general tienden a reflejar diferentes estilos de vida y vida familiar.

-Liaison International: agencia de servicios, dedicada al material de tipo publicitario con un fondo de 4.000.000 de fotografías, 5.000 de las cuales son consultables en internet.

—Look: fundada en 1990 por un grupo de fotógrafos alemanes y cuya colección engloba más de $1 \mathrm{mi}-$ llón de imágenes, procedentes de la obra de 28 fotógrafos. El archivo ahonda en conceptos relacionados con temas de la vida cotidiana, estilos de vida, viajes, deportes y la naturaleza.

—Magnun: Magnum Photos, fundada en 1947 por Andrej Friedmann (Robert Capa), Henri CartierBresson, George Rodger y David "Chim" Seymour es posiblemente la cooperativa de fotógrafos más prestigiosa de todo el mundo. En la actualidad cuenta con 44 socios, con una red de corresponsales y afiliados distribuidos por todo el mundo. Los cuales llevan a cabo sus propios proyectos editoriales y culturales, a la vez que cumplen con los más variados encargos que reciben de clientes procedentes de los campos de prensa, editorial, publicidad y cultura. A su vez organiza exposiciones y publica libros con los trabajos más destacados de sus miembros.

-Picturesque: agencia de fotografía especializada en material tipo "stock", con una extensa colección sobre el Caribe. El Picturesque gold set, su producto estrella, es una cuidada selección de las fotografías más impactantes.
—Vandystadt: se creó hace 20 años y está especializada en el mundo del deporte, diversificando sus actividades con la organización de exposiciones de fotografía, la edición de libros de arte de temática deportiva, así como la producción de fotografías publicitarias (no necesariamente relacionadas con el deporte). No tiene sistema de búsqueda online y sólo ofrece enlaces a Camera Press y Liaison International (por medio de contraseña y nombre de usuario gestionados por Zardoya), Picturesque (libre acceso), y se anuncia que pronto se ofrecerá un enlace a Look. También se ofrecen catálogos gratis en papel con los gastos de envío a cargo del solicitante: uno de Liaison International, otro de Look y dos de Picturesque.

http://www.zardoya.com

\section{Bibliografía}

Codina, L. "Fundamentos para la organización de un banco de fotografías". En: El profesional de la información, 2000, abril, v. 9, n. 4, pp. 31-34.

Evans, P.; Wurster, T. S. Blown to bits. How the new economics of information transforms strategy. Boston: Harvard Business Scholl Press, 1999, pp. 28-29. Isbn 87584877.

Engh, R. SellPhotos.Com. Cincinnati: Writers Digest Books, 1999, 176 pp. Isbn 0898799449.

Eiseman, L. Pantone's guide to communicating with color, 2000. Cincinnati: Writers Digest Books, 144 pp. Isbn 0966638328

Gutiérrez Escera, A. "La transmisión de imágenes fotográficas". En: La imatge i la recerca històrica: ponències i comunicacions. $4^{\text {es }}$ jornades Antoni Varés, Girona, 1996.

García Gutiérrez, A. (ed.). Introducción a la documentación informativa y periodística. Sevilla: MAD, 1999, 509 pp. Isbn 8483114607.

González, R. C.; Woods, R. E. Tratamiento digital de imágenes. Madrid: Addison-Wesley; Díaz de Santos, 1996. Isbn 8479782749.

Jackson, J. The one-stop digital shop: why the picture researcher's life just got so much easier. En: Information world review, 1998, noviembre, n. 141, p. 48 .

Langford, M. Fotografía básica. Barcelona: Ediciones Omega, 1999. Isbn 8428209006.

Marcos Recio, J. C. La documentación electrónica en los medios de comunicación. Madrid: Fragua, 1999. Isbn 8470741101.

Robledano Arillo, J. "Documentación fotográfica en medios de comunicación social”. En Moreiro, J. A. (coord.); Caridad, M. [et al.]. Manual de documentación informativa. Madrid: Cátedra, 2000, pp. 183-290. Isbn 8437617987.

Sánchez Vigil, J. M. El universo de la fotografía. Prensa, edición, documentación. Madrid: Espasa-Calpe, 1999. Isbn 8423991954.

Valle Gastaminza, F. del. Manual de documentación fotográfica. Madrid: Síntesis, 1999. Isbn 8477386897.

Willen Brown, S. Indexing photographs. Consultado en: 25-09-00. http://metalab.unc.edu/slanews/archiving/VE98/presentation.htm 